\title{
Socio-economic and demographic factors associated with snacking behavior in a large sample of French adults
}

Wendy Si Hassen ${ }^{1 *}$, Katia Castetbon², Sandrine Péneau ${ }^{1}$, Christine Tichit ${ }^{3}$, Anouar Nechba ${ }^{2}$, Aurélie Lampuré , France Bellisle ${ }^{1}$, Serge Hercberg ${ }^{1,4}$ and Caroline Méjean ${ }^{1,5}$

\begin{abstract}
Background: Few studies have specifically focused on demographic and socio-economic characteristics associated with snacking in adults, whereas their identification could be useful for defining effective public health measures. The aim of our study was to assess the associations of these factors with daily snacking behavior and its dietary quality.

Methods: This cross-sectional study included 84,692 women and 23,491 men from the NutriNet-Santé cohort study. Occurrence of snacking, energy intake from snacks, snack nutrient, and energy densities were assessed using 24-h dietary records of weekdays at baseline. Associations between socio-economic and demographic factors (age, presence of children in the household, education, income, occupation), and snacking behavior were examined using multivariable logistic regression and analysis of covariance, stratified by sex and adjusted for total daily energy intake.

Results: Older individuals were more likely to snack during the day in both sexes while individuals with primary education $(\mathrm{OR}=0.79(0.71 ; 0.87)$ in women; $\mathrm{OR}=0.71(0.60 ; 0.83)$ in men), female employees $(\mathrm{OR}=0.94(0.89 ; 0$. 99), and self-employed women were less likely to snack during the day. Older individuals, in particular middle-aged subjects, had higher snack nutrient density, and lower energy intake and density from snacks compared with younger adults. Presence of a child in the household was associated with higher energy density, lower nutrient density (in women), and lower energy intake from snacks (in men), compared with those who lived without a child in household. In low income individuals and manual workers, snacks had lower nutrient density and higher energy content than in higher socioeconomic categories. At last, energy intake from daily snacking occasions was higher in women with low education level.
\end{abstract}

Conclusions: Although snacking was less prevalent in low socioeconomic categories and young adults, their snacks had higher energy content and were of poorer nutrient density. Such findings provide useful information on mechanisms of social disparities in dietary behavior.

Trial registration: This study was conducted according to the guidelines laid down in the Declaration of Helsinki. All procedures were approved by the Institutional Review Board of the French Institute for Health and Medical Research (IRB Inserm No0000388FWA00005831) and the French Data Protection Authority (Commission Nationale Informatique et Libertés No.908450 and No.909216). Clinical Trial no. NCT03335644

Keywords: Snack, Snacking, Socioeconomic position, Demographic factors, Nutritional content, Dietary behavior, Eating behavior

\footnotetext{
* Correspondence: w.sihassen@eren.smbh.univ-paris13.fr

${ }^{1}$ Centre de Recherche en Epidémiologie et Statistique, Equipe de Recherche en Epidémiologie Nutritionnelle (EREN), Inserm (U1153), Inra (U1125), Cnam, Université Paris 13, 74 rue Marcel Cachin, F-93017 Bobigny, France Full list of author information is available at the end of the article
} 


\section{Background}

Snacking appears to be common in Western countries [13]. The effects of snacking and eating frequency on dietary quality, nutrient intake, and weight status are unclear [4-7]. In some studies, snacking or high eating frequency are associated with better dietary quality and higher intake of vitamins, potassium or magnesium [4, 8-11]. In contrast, one Scandinavian study showed that, when snacks contribute to most of the daily energy, the nutrient quality of diet is lower compared to the diet of individuals for which energy intake from snacks is lower [12]. Other studies have shown that snacking may represent a high percentage of daily energy intake (up to 30-35\%) [5] and may contribute to a positive energy balance $[7,13,14]$ that could consequently lead to weight gain $[15,16]$.

Identification of population subgroups with frequent and unhealthy snacking behavior may help public health policymakers to target the dietary behavior of populations in a more focused and efficient manner. Some studies have assessed demographic and socioeconomic differences for snacking $[8,12,13,17-20]$ but they have mostly focused on snacking frequency $[8,13,18]$. These studies found that age was inversely associated with snack frequency and snacking behaviors $[8,12,18,20]$. Sex differences in snacking behavior in adults have been reported but are contradictory $[8,13,17-19]$. Results on the associations between the presence of a child in the household and snacking behavior remain scarce and unclear: one study found that having a child in the household was inversely associated with a "snacker pattern" in women [20] while another study found no significant association between snack frequency and having children [18]. Regarding socioeconomic position, previous works on education showed equivocal results $[8,12,18,19]$ while income seems to be positively associated with snacking frequency $[8,19]$. Regarding occupation, male manual workers were more likely to have a diet in which snacks contribute to most of the daily energy, than non-manual workers [12].

However, little is known about relationships between the nutritional quality of snacks and socioeconomic and demographic profiles $[18,19]$. The few studies that investigated nutritional quality of snacks among these subgroups focused only on energy content of snacks or main groups consumed during these occasions. The aims of our study were therefore to assess associations between demographic and socioeconomic factors and occurrence of snacking, on one hand, and nutritional quality of snacks (energy content and nutrient and energy densities), on the other hand, in a large sample of French adults.

\section{Methods}

\section{Population and design}

Subjects were participants in the NutriNet-Santé study, a large web-based prospective observational cohort launched in France in May 2009 and for which recruitment of participants is still ongoing. The study was implemented in the French general population targeting internet-using volunteers aged $\geq 18$ years. The design, methods and rationale have been described previously [21]. Briefly, participants were included in the cohort once they had completed a baseline set of questionnaires assessing dietary intake, physical activity, socioeconomic, and health status. As part of their follow-up, the participants completed the same set of questionnaires every year. This study was conducted according to the guidelines laid down in the Declaration of Helsinki, and all procedures were approved by the Institutional Review Board of the French Institute for Health and Medical Research (IRB Inserm No. 0000388FWA00005831) and the French Data Protection Authority (Commission Nationale Informatique et Libertés No. 908450 and No. 909216). Electronic informed consent was obtained from all participants.

This cross-sectional study focused on participants included in the NutriNet-Santé cohort study between May 2009 and January 2015 living in the mainland France, who had completed at least two 24-h dietary records at baseline, and with no missing data on socioeconomic and demographic factors. For each individual, we used data at baseline, collected between 2009 and 2015, according to the date of inclusion of the participant. Only weekday $24 \mathrm{~h}$ records were used in our analysis.

\section{Data collection, data computation and statistical analysis Demographic and socioeconomic data}

Socioeconomic and demographic data were collected at baseline using a web-based self-completed questionnaire, using categories consistent with the French National Institute of Statistics definitions [22-24]. Age and presence of children in the household ( $\mathrm{Yes} / \mathrm{No}$ ) were collected. Four categories of age were used: < 30 y, 31-45y, and 46$60 \mathrm{y}$ and $>60 \mathrm{y}$. The highest attained diploma defined the educational level [22] and four categories were used in the analysis: primary education, secondary education, undergraduate (corresponding to up to 3 years after high school diploma), and postgraduate ( $>3$ years after high school diploma). Occupation was coded into 6 classes: never employed (homemakers, students, and disabled), manual workers, employees, intermediate professions (e.g., technicians, skilled employees, teachers, nurses), self-employed (craftsman, shopkeeper, company manager, and farmer), and managerial staff. When subjects were unemployed or retired, the occupational category of their last job was recorded. Participants reported their monthly household income including salary, social benefits, family allowance, and rental income. The reported monthly household income was then divided by the number of household units (HU): $1 \mathrm{HU}$ is attributed for the first adult in the household, $0.5 \mathrm{HU}$ for other 
persons aged $\geq 14$ years, and $0.3 \mathrm{HU}$ for children < 14 years [25]. The following four categories of monthly income were used: <1200€, 1200-1800€, 1800-2700€, and $>2700 €$ per HU plus a category for individuals who were unwilling to answer.

\section{Assessment of dietary behaviors}

At baseline, participants were invited to fill in 3 nonconsecutive web-based 24-h dietary records, randomly assigned over a 2 -week period ( 2 weekdays and 1 weekend day) $[21,26,27]$. The dietary record was completed via a validated interactive interface and designed for selfadministration on the Internet [28]. The web-based dietary assessment method relies on an event-based approach, recording all foods and beverages (type and quantity) consumed at breakfast, lunch, dinner, and all other eating occasions, thus leading to 4 initial categories of eating occasions. They estimated portion sizes for each reported food and beverage according to standard measurements (e.g., home containers, grams indicated on the package) or using validated photographs [29]. Values for energy, macronutrients, and micronutrients were estimated using published nutrient databases and completed for recent market foods and recipes [30]. Energy-underreporting participants were identified by the method proposed by Black [31]. Briefly, basal metabolic rate (BMR) was estimated by Schofield eqs. [32] according to sex, age, weight and height collected at enrolment in the study. BMR was compared to energy intake taking into account the physical activity level. A physical activity level of 1.55 was used to identify energy-underreporting subjects [31]. They were consequently excluded for analysis.

Because of variable and unusual eating behaviors on the weekends, we focused our analysis on weekdays. We categorized the eating occasions according to their nutritional content and self-reported time. Eight categories of eating occasions were used: 3 main meals (breakfast, lunch, dinner) and 5 snacks (morning, midday, afternoon, evening and night snacks). Daily overall snacking was defined by the occurrence of at least one snacking occasion during the $24 \mathrm{~h}$ record. All snacking occasions occurring at different times during a $24 \mathrm{~h}$ record were then pooled to define the nutritional content of overall daily snacking. A binary variable (Yes/No) indicating whether the individual had snacked at least once during the day was computed.

\section{Energy intake and energy density}

Energy intake of one snacking occurrence was calculated by summing energy intake associated with all food items consumed during this eating occasion. Energy intake from daily snacking occasions was calculated by summing the energy intake of all snacking occasions. Energy density was defined as the ratio of total energy (in kcal) by the weight (in g) of daily snack"100 [33]. Low-calorie beverages (first decile of energy per $100 \mathrm{~g}$ ) were excluded of the computation.

\section{Nutrient density}

To assess daily nutrient density of snacks, the NRF9. $3_{100}$ kcal index [34] was used. The NRF9.3 is a score based on nine beneficial nutrients (protein, fibre, vitamins A, C, and $\mathrm{E}$ ) and minerals (magnesium, potassium, iron, and calcium), and three nutrients that should be limited (saturated fat, added sugars, and sodium). Daily values defined by the Food and Drug Administration [35] were used to score each eating occasion using the NRF9.3 algorithm. A high positive score reflects dietary intake that provides large amounts of beneficial nutrients.

Algorithm: NRF9.3 $3_{100} \mathrm{kcal}[34]=\sum_{\mathrm{i}=1-9}\left(\right.$ Nutrient $_{\mathrm{i}} /$ $\left.\mathrm{RDV}_{\mathrm{i}}\right)^{* 1} 100-\sum_{\mathrm{i}=1-3}\left(\right.$ Nutrient $\left._{\mathrm{i}} / \mathrm{MDV}_{\mathrm{i}}\right) * 100$

$\mathrm{RDV}=$ recommended daily values; MDV: maximum daily values.

\section{Statistical analyses}

Comparisons of socioeconomic and demographic characteristics and dietary intakes at baseline between men and women were performed using Student's t-tests and Chi-square tests, as appropriate.

Independent associations between socioeconomic and demographic factors and snacking behaviors were examined using multivariable logistic regression for occurrence of snacking (at least one snacking occasion), and analysis of covariance for quantitative variables (nutrient and energy densities, and energy intake from daily snacks). The highest educated group, the highest income group, the managerial staff group, the lowest age class group, and the absence of children in the household were used as references in logistic regressions. Analysis of covariance is used to compare response means among socioeconomic and demographic groups (categorical socioeconomic and demographic variables) adjusted for a quantitative variable (total daily energy intake as covariate), thought to influence the outcome (nutrient density, energy density and energy intake from snacks as dependent variables respectively). Collinearity between the three SEP indicators was investigated by examining the variance inflation factor. First, models assessing the associations between each demographic and socioeconomic factor and each outcome (nutrient and energy densities and energy intake from daily snacks) were performed. Then, the demographic and socio-economic indicators were included all together in logistic and covariance models. All models were adjusted for total daily energy intake. As snacking occurrence and socioeconomic and demographic indicators have been associated with skipping meals [36-39], we considered the three binary variables (having breakfast (Yes/No), having 
lunch (Yes/No), and having dinner (Yes/No)) as confounding variables. These variables were therefore included in model of snacking occurrence. All analyses were performed separately in men and women since interactions were found. Data treatment and statistical analyses were performed using SAS (version 9.3; SAS Institute, Inc., Cary, NC, USA).

\section{Results}

\section{Description of the sample}

Among 144,746 individuals with available dietary data at baseline, we excluded individuals who were pregnant, those who did not provide at least two 24-h dietary records ( $n=19,987 ; 13.8 \%)$, underreporting subjects $(n=15,785$; $10.9 \%$ ), and individuals with missing data for sociodemographic and economic variables $(n=791 ; 0.7 \%)$ - leaving 108,183 individuals for analysis $(84,692$ women and 23,491 men). For all factors considered, differences between men and women were found (Table 1). In women, percentages of younger respondents (18-30 years), those with undergraduate education, employees, and never-employed, those with the lowest income, and those living in household with at least one child were higher than in men; conversely, higher percentages of older adults ( $>60$ years), those with post-graduate education, managerial professions and self-employed persons, and those with the highest income level were observed in men compared with women (Table 1).

\section{Snacking behaviors}

Percentages of individuals having at least one snack and information regarding snack frequency are shown in Table 2. Higher occurrence of snacking during weekdays was observed in women compared to men $(73.5 \%$ vs $65.4 \%, p<0.0001)$. Among men and women who snacked, more than $80 \%$ had one or two daily snacks (Table 2). Means values regarding descriptive snacking characteristics of the sample are shown in Table 2 (energy intake, nutrient density, energy density and contribution to daily energy intake). Mean energy intake from daily snacks and mean nutrient density of snacks in women were lower than in men while mean energy density was higher (energy, mean (SD): 231 (247) kcal in women vs 296 (309) kcal in men; nutrient density, mean

Table 1 Characteristics of participants in the NutriNet Santé Study included in the present study $(N=104,183 ; 23,491$ men and $84,692$ women) $)^{a}$

\begin{tabular}{|c|c|c|c|c|}
\hline & & $\begin{array}{l}\text { Men }(N=23,491) \\
\% \text { or mean }(S D)\end{array}$ & $\begin{array}{l}\text { Women }(N=84,692) \\
\% \text { or mean }(S D)\end{array}$ & $\begin{array}{l}P \text { - value for chi-square or student } \\
t \text { test analysis }\end{array}$ \\
\hline \multirow[t]{4}{*}{ Age class } & $\leq 30 y$ & 17.8 & 28.5 & $<0.0001$ \\
\hline & $31-45$ & 28.2 & 31.0 & \\
\hline & $46-60$ & 27.9 & 29.0 & \\
\hline & $>60 y$ & 26.1 & 11.5 & \\
\hline \multirow[t]{2}{*}{ Presence of children in the household } & No child in the household & 70.9 & 64.4 & $<0.0001$ \\
\hline & $\begin{array}{l}\text { At least one child in the } \\
\text { household }\end{array}$ & 29.1 & 35.6 & \\
\hline \multirow[t]{4}{*}{ Educational level } & Postgraduate level & 38.4 & 31.3 & $<0.0001$ \\
\hline & Undergraduate level & 24.6 & 32.3 & \\
\hline & Secondary school & 33.5 & 33.7 & \\
\hline & Primary school & 3.5 & 2.7 & \\
\hline \multirow[t]{5}{*}{ Household income per consumption unit } & $>2700$ euros & 31.5 & 20.6 & $<0.0001$ \\
\hline & $1800-2700$ euros & 25.2 & 22.2 & \\
\hline & 1200-1800 euros & 23.1 & 25.0 & \\
\hline & $<1200$ euros & 13.1 & 19.0 & \\
\hline & Unwilling to declare & 7.1 & 13.2 & \\
\hline \multirow[t]{6}{*}{ Occupation } & Managerial staff & 50.0 & 29.7 & $<0.0001$ \\
\hline & Self-employed & 5.3 & 3.3 & \\
\hline & Intermediate profession & 22.8 & 26.7 & \\
\hline & Employee & 14.2 & 34.0 & \\
\hline & Manual worker & 5.3 & 1.9 & \\
\hline & Never employed & 2.4 & 4.4 & \\
\hline
\end{tabular}


Table 2 Snacking characteristics of participants in the NutriNet Santé Study included in the present study $(N=104,183 ; 23,491$ men and 84,692 women) ${ }^{a}$

\begin{tabular}{|c|c|c|c|}
\hline & $\begin{array}{l}\text { Men }(N=23,491) \\
\% \text { or mean }(S D)\end{array}$ & $\begin{array}{l}\text { Women }(N=84,692) \\
\% \text { or mean }(S D)\end{array}$ & $\begin{array}{l}P \text { - value for chi-square or student } \\
\mathrm{t} \text { test analysis }\end{array}$ \\
\hline Having at least one snack & 65.4 & 73.5 & $<0.0001$ \\
\hline $\begin{array}{l}\text { Frequency of snack among individuals having at least one snack during } \\
\text { the record }\end{array}$ & & & $<0.0001$ \\
\hline 1 snack per day & 55.0 & 54.9 & \\
\hline 2 snacks during the day & 30.1 & 31.6 & \\
\hline 3 snacks during the day & 11.3 & 10.9 & \\
\hline 4 snacks during the day & 3.2 & 2.3 & \\
\hline 5 snacks during the day & 0.4 & 0.3 & \\
\hline Daily energy intake from snacking occasions $(\mathrm{kcal})^{\mathrm{b}}$ & $269.3(309.0)$ & $231(246.6)$ & $<0.0001$ \\
\hline Contribution of energy intake from snacking to total daily energy $b, c$ & $11.8(12.4)$ & $12.8(12.1)$ & $<0,0001$ \\
\hline Daily mean nutrient density of snacks ${ }^{b}$ & $115.3(274.8)$ & $103.5(299.1)$ & $<0.0001$ \\
\hline $\begin{array}{l}\text { Daily mean energy density (without low caloric beverages) of snacks } \\
(\mathrm{kcal} / 100 \mathrm{~g})^{\mathrm{b}}\end{array}$ & $224.5(170.2)$ & $231.9(170.8)$ & $<0.0001$ \\
\hline
\end{tabular}

${ }^{a}$ Data used in the analysis were collected for each participant at inclusion in the cohort

${ }^{b}$ Among individuals having at least one snack during the record

${ }^{c}$ Computed as (energy intake from daily snacks/total daily energy intake)*100

(SD): 104 (299) in women and 115 (275) in men; energy density (mean (SD): 232 (171) in women and 225 (170) in men; all $p$-values $<0.0001$ ) (Table 2). In both sexes, among individuals who snack, snacking had an important contribution to total daily intake (approximately $12 \%$ in men and $13 \%$ in women (means)) (Table 2).

Median of energy intake from daily snacks of snacks in women were lower than in men while energy density and contribution to total daily intake were higher (energy intake, median (interquartile range): 162.0 (252.7) kcal in women vs 173.7 (300.2) kcal in men; energy density (median (interquartile range):170.8 (334.0) in women and 162.9 (338.2) in men; contribution to total daily intake median (interquartile range): 9.7 (14.1) in women and 8.2 (13.4) in men) (Additional file 1: Table S1).

\section{Age}

In both sexes, we observed bell-shape associations between age and occurrence of snacking, and between age and nutrient density of snacks (Tables 3 and 4). Middleaged subjects, in particular those aged 31-45y and 46-60y were more likely to have at least one snacking occasion during weekdays compared to younger subjects (Table 3 ). Nutrient density of snacks of middle aged subjects was higher compared to younger adults (range according to sex: 103 to 122 in individuals aged $31-45 y$ and 112 to 115 in individuals $46-60$ y vs. 73 to 97 in participants aged 18$30 y$ ) (Table 4). In both sexes, energy density of snacks and energy intake from daily snacks decreased with age (range (youngest to oldest individuals); energy density 238 to $219 \mathrm{kcal} / 100 \mathrm{~g}$ in women $(p<0.0001)$ and 226 to $213 \mathrm{kcal} / 100 \mathrm{~g}$ in men $(p=0.004)$; energy intake from snacks: 266 to $220 \mathrm{kcal}$ in women $(p<0.0001)$ and 341 to $257 \mathrm{kcal}$ in men $(p<0.0001))$ (Table 4$)$.

\section{Presence of children in the household}

In both sexes, no significant association between the presence of children in the household and snacking occurrence during the day was found (Table 3). In women only, daily nutrient density of snacks was lower in individuals living in a household with children compared to those living with no children (mean (SE): 89.9 (3.5) vs 99.9 (2.9) $p=0.0007$ ) (Table 4). In both sexes, daily energy density of snacks was higher when at least one child was present in the household (in women (mean (SE)): 234.9 (2.1) kcal/100 g vs 220.5 (1.7) kcal/ $100 \mathrm{~g}$ ) (Table 4). In men only, energy intake from daily snacking was lower in men who lived with a child than in those living with no children (Table 4).

\section{Socioeconomic position (SEP)}

Overall, variance inflation factor of each SEP indicator was between 1.01 and 1.64, showing that SEP indicators were not collinear.

\section{Education}

Low education was associated with lower occurrence of snacking during weekdays in both sexes (Table 3). In both sexes, energy density of snacks was lower in low education groups compared to the postgraduate level ($20 \mathrm{kcal} / 100 \mathrm{~g}$ between individuals with primary school level and those with postgraduate level, $p<0.0001$ ) (Table 4). In women only, energy intake from daily snacks decreased with education level $(+29 \mathrm{kcal}$ in 
Table 3 Associations ${ }^{a}$ between socioeconomic and demographic characteristics and snacking occurrence in women ( $\left.N=84,962\right)$ and men $(N=23,491)^{b}$

\begin{tabular}{|c|c|c|c|c|c|c|c|}
\hline & & \multicolumn{3}{|c|}{ Women } & \multicolumn{3}{|l|}{$\underline{\text { Men }}$} \\
\hline & & $\begin{array}{l}\text { Odds } \\
\text { Ratio }\end{array}$ & $\begin{array}{l}\text { Confidence Interval } \\
\text { (Cl 95\%) }\end{array}$ & $P$-value & $\begin{array}{l}\text { Odds } \\
\text { Ratio }\end{array}$ & $\begin{array}{l}\text { Confidence Interval } \\
\text { (Cl 95\%) }\end{array}$ & $P$-value \\
\hline \multirow[t]{4}{*}{ Age class } & $\leq 30 y$ & 1 & & $<0.0001$ & 1 & & 0.0001 \\
\hline & $31-45$ & 1.24 & $1.18 ; 1.30$ & & 1.17 & $1.06 ; 1.29$ & \\
\hline & $46-60$ & 1.35 & $1.29 ; 1.41$ & & 1.11 & $1.01 ; 1.22$ & \\
\hline & $>60 y$ & 1.14 & $1.08 ; 1.21$ & & 0.98 & $0.89 ; 1.08$ & \\
\hline \multirow{2}{*}{$\begin{array}{l}\text { Presence of children in the } \\
\text { household }\end{array}$} & No child at in the household & 1 & & 0.3 & 1 & & 0.2 \\
\hline & $\begin{array}{l}\text { At least one child in the } \\
\text { household }\end{array}$ & 1.02 & $0.98 ; 1.06$ & & 1.05 & $0.98 ; 1.13$ & \\
\hline \multirow[t]{4}{*}{ Educational level } & Postgraduate level & 1 & & $<0.0001$ & 1 & & $<0.0001$ \\
\hline & Undergraduate level & 0.94 & $0.90 ; 0.98$ & & 0.97 & $0.90 ; 1.05$ & \\
\hline & Secondary school & 0.82 & $0.79 ; 0.87$ & & 0.87 & $0.80 ; 0.94$ & \\
\hline & Primary school & 0.79 & $0.71 ; 0.87$ & & 0.71 & $0.60 ; 0.83$ & \\
\hline \multirow{5}{*}{$\begin{array}{l}\text { Household income per } \\
\text { consumption unit }\end{array}$} & $>2700$ euros & 1 & & 0.04 & 1 & & 0.2 \\
\hline & $1800-2700$ euros & 1.04 & $0.99 ; 1.09$ & & 0.97 & $0.90 ; 1.05$ & \\
\hline & $1200-1800$ euros & 1.03 & $0.98 ; 1.08$ & & 0.98 & $0.90 ; 1.06$ & \\
\hline & $<1200$ euros & 0.98 & $0.92 ; 1.03$ & & 0.90 & $0.81 ; 1.00$ & \\
\hline & Unwilling to declare & 0.97 & $0.92 ; 1.03$ & & 0.89 & $0.79 ; 1.01$ & \\
\hline \multirow[t]{6}{*}{ Occupation class } & Managerial staff & 1 & & $<0.0001$ & 1 & & 0.02 \\
\hline & Self-employed & 0.89 & $0.82 ; 0.98$ & & 0.93 & $0.82 ; 1.06$ & \\
\hline & Intermediate profession & 1.06 & $1.01 ; 1.11$ & & 1.11 & $1.03 ; 1.21$ & \\
\hline & Employee & 0.94 & $0.89 ; 0.99$ & & 1.06 & $0.96 ; 1.16$ & \\
\hline & Manual worker & 0.94 & $0.83 ; 1.06$ & & 1.14 & $0.99 ; 1.32$ & \\
\hline & Never employed & 0.97 & $0.89 ; 1.06$ & & 1.20 & $0.97 ; 1.48$ & \\
\hline
\end{tabular}

a Using multivariable logistic regression adjusted on total energy intake. The demographic and socio-economic factors were included simultaneously in the models ${ }^{\mathrm{b}}$ Data used in the analysis were collected for each participant at inclusion in the cohort

snacks of women with primary school level compared to those with postgraduate level) (Table 4).

\section{Occupation}

In both sexes, individuals with intermediate professions were more likely to snack during weekdays than managerial staff participants (Table 3). In women, employees and self-employed individuals were less likely to snack than women with managerial positions (Table 3). Daily nutrient density of snacks was lower in manual workers and employees compared to those belonging to the managerial category ( -20 to -40 according to sex) (Table 4).

Energy intake from daily snacks of manual workers and employees was higher compared to individuals belonging to the managerial category $(+20$ to $+30 \mathrm{kcal}$ in women and +34 to $+55 \mathrm{kcal}$ in men) (Table 4). Energy intakes from daily snacks are minimal in individuals with managerial professions (mean (SE): 220.3 (2.5) in women and 261.1 (5.5) in men) and maximal for manual workers (mean (SE): 252.7 (6.8) in women and 316.4 (10.5 in men) among professionally active individuals.

\section{Income}

No significant difference in snacking occurrence during weekdays was found according to income levels (Table 3). Daily nutrient density of snacks was lower and energy intakes of daily snacks was higher in low income individuals compared to those with higher income (Table 4). For instance, we observed that daily snacks of individuals with the lowest income had a mean additional energy intake of $40 \mathrm{kcal}$ in women and $55 \mathrm{kcal}$ in men compared to snacks of those with the highest income. In women only, energy density increased with income (Table 3).

\section{Discussion}

This study presents an original assessment of differences in both occurrence and nutritional quality of snacking according to socioeconomic and demographic factors in adults. Compared to younger adults, older individuals were more likely to snack and the nutritional quality of their snack was higher. Presence of children in the household was associated with higher energy density of snacks in both sexes and lower nutrient density of 


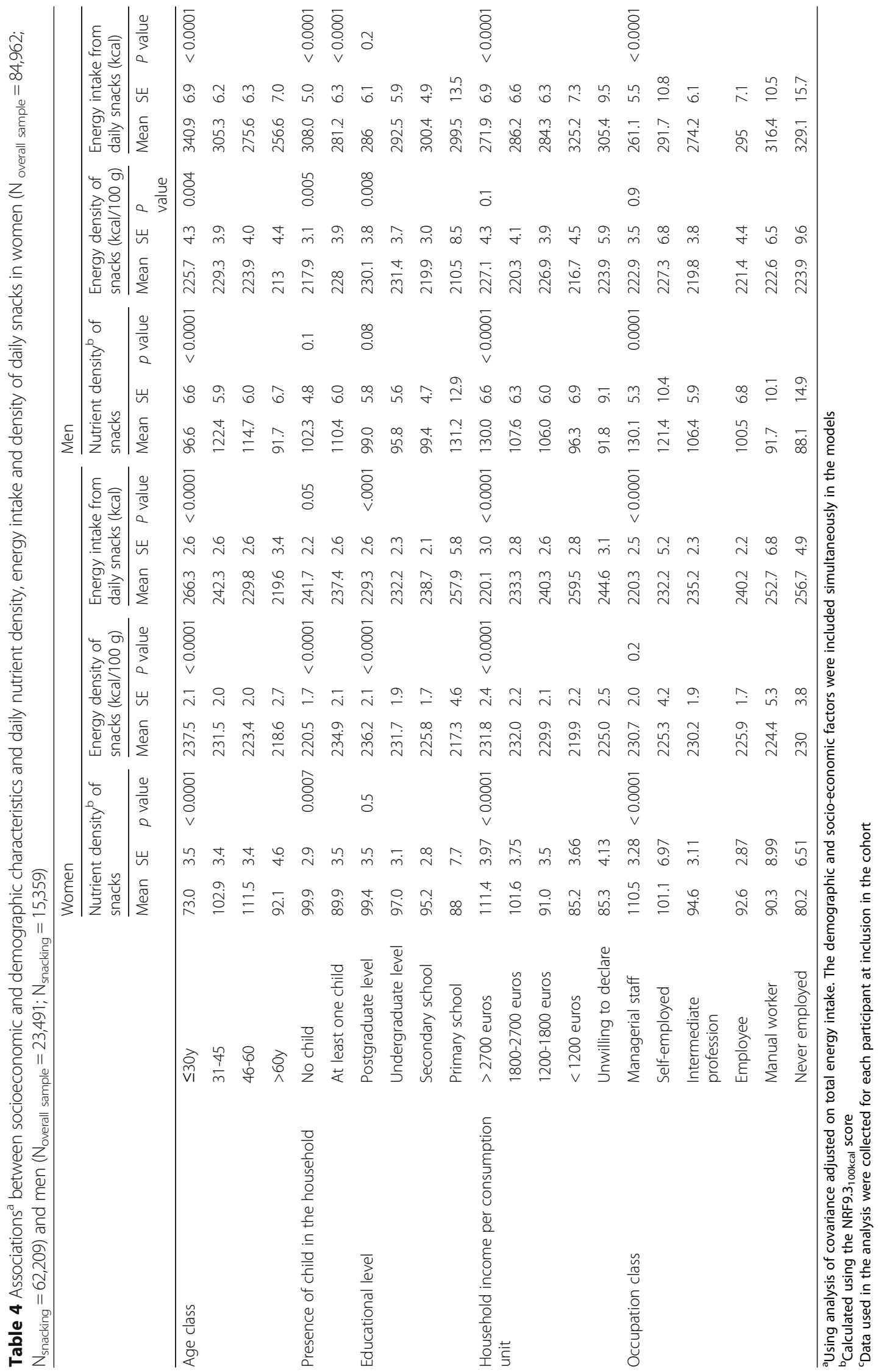


snacks in women. Snacking behavior was less prevalent in low educated individuals and varied according to occupation levels. However, compared with those from the highest socioeconomic groups, nutritional quality of snacks in low socioeconomic groups was lower (lower nutrient density and higher energy intake from snacks).

\section{Age}

In our study, middle aged individuals were more likely to snack during the day. A previous work has shown that age was inversely associated with snack frequency while another study showed that the higher snack frequency was found among individuals aged 40-59y [8]. Individuals aged $30 \mathrm{y}$ and more are more likely to be in the workforce compared with younger adults or individuals aged $60 \mathrm{y}$ or more and the workplace has been associated with snacking [40]. Indeed, self-control imposed by work, emotional affects, daily hassles, and working hours along with social context of eating and availability of foods at work could lead working adults to snack during the day, even in the absence of physiological hunger [41-44]. Higher nutritional quality of snacks of middleaged individuals are linked to higher contribution of fruits, hot beverages, and lower contribution of fatty and sweet products to the energy intake of daily snacks in these age classes (data not shown). Nutrient density of men aged $60 \mathrm{y}$ or more was lower than that of the youngest male individuals because alcohol contribution to snack energy is higher in men aged 60y and more (data not shown).

\section{Presence of children in the household}

Presence of at least one child in the household was not significantly associated with snacking occurrence while it was associated with lower nutritional quality of snacks, particularly in women. Along with increased availability at home [45-49], adults may consume products usually eaten by children during snacks such as biscuits, bread, pastries, cereals or chocolate [50], contributing to the lower nutritional quality. In further analyses (Additional file 2: Table S2), we observed in women that having children in the household was associated with a lower contribution of fruits and with a higher contribution of sugary products and fatty sweet foods to total energy intake from snack. In addition, in our cohort, women who had at least one child were more likely to have a strong liking for the fat-and-sweet sensation compared with those without children [51].

\section{Socioeconomic position}

In contrast with previous studies [12, 18], our findings showed that individuals belonging to low SEP (education and occupation) were less likely to snack. Such differences could be explained by heterogeneity in study design. Indeed, our study did not investigate snacking frequency but occurrence of snacking and the definition of snacking was not based on the participant's selfdeclaration of "snacks" in contrast to previous works. In addition, contribution of snacking to total energy intake seems to be considerably higher in countries such as the USA, the Netherlands or Scandinavian countries (up to $35 \%$ of daily energy) $[5,52]$ than in France (around 13\% in our sample, $18 \%$ in another French study [1]). Snacking behaviors are thus more anchored in those countries than in France, where the "three main meals" pattern remains important [53]. Consequently, in these countries, snacking behaviors are more likely to reflect socioeconomic disparities in overall diet whereas difference regarding snacking occurrence in our study may rather show behavioral differences among social groups. In line with previous studies showing that low socioeconomic status is associated with poorer nutrient intakes and food intakes [54-56], low SEP individuals had overall lower nutritional quality of snacks. As snacks of low SEP individuals had higher energy content than those of high SEP, snacking of low SEP might lead particularly to excess daily energy intake and consequently, to positive energy balance which is a risk factor of weight gain [15]. However, the snacks of high SEP individuals had higher energy density compared with those of the lower SEP categories. These data suggest that high SEP individuals consume more energy dense products but in a small amount.

Employees and self-employed individuals were less likely to snack in our study compared with managerial staff individuals. Managerial individuals may have extensive discretion in organising their work, leaving them more occasions to snack. In addition, they are more likely to have more conviviality eating occasions (meeting, cocktail and farewell parties, conference break...) in the professional environment $[57,58]$.

An important body of literature has concluded that a high education level is associated with healthy dietary patterns including a greater consumption of fruits, vegetables, and whole-grain foods $[55,56,59]$. However, our results regarding nutritional quality of snacking are more mixed. Individuals with lower education levels had snacks with lower energy density compared to those of higher education levels. In further analyses (data not shown), we observed that fatty sweet products had a lower contribution to energy intake from daily snacks in individuals with lower education levels than in highly educated persons. Our web-based design and our method of assessment of dietary behaviors may have reduced desirability bias in high educated individuals, leading them to report more accurately their consumption of energy-dense products, even if these individuals are aware of its health impact $[60,61]$. 
We found that lower income was associated with lower nutrient density of snacks. The higher cost of nutrient-dense products may lead individuals with low income to choose foods with lower nutritional value and may explain the differences in nutritional quality of snack according to income classes [62]. In addition, the perception of the association between nutrition and health can vary according to income level. Compared to low income individuals, high income individuals are more exposed to nutrition knowledge and therefore more likely to make food choices that take health consideration into account [63-65].

As snacking seems to be a common behavior that contributes significantly to daily energy intake (12$13 \%$ of total energy intake among individuals who snack), it could impact negatively diet quality and health. Some individuals seem more likely to snack during the day such as older high educated or high occupational individuals. The present study showed that lower nutritional quality of snacks (particularly, nutrient density and energy intake) is associated with presence of child in women only, younger age and low socioeconomic position. This suggests less healthy behaviors in these specific subgroups of the French population. When focusing on snacking, policy makers and practitioners should integrate the importance of these determinants in their recommendations. Since snacking is prevalent and could help to avoid overconsumption at the subsequent meal [66], it could be interesting to promote healthy snacking (fruits, vegetables, low fat and low sugar dairy products...), particularly among individuals of lower socioeconomic position. For instance, implementation of actions through professional networks or short education programs should be considered. In addition, actions focusing on food reformulation and changes in food supply could help reducing socioeconomic disparities in nutritional quality of snacks. Among possible changes, easy to read frontof-pack labelling based on nutrient profiling would allow consumers to compare snack products and might encourage food industries to improve the nutritional quality of their products.

\section{Strengths and limitations}

Since the NutriNet-Santé cohort includes volunteers, more subjects were women, belonged to high education group and had a healthier lifestyle [67, 68], and were probably more interested in nutrition than the general population. Thus, caution is needed when interpreting and generalizing results. A web-based design may affect internal validity by inducing misreporting. However, studies investigating the validity of our web-based, selfreported dietary record tool against biomarkers showed that our tool performs well at estimating several nutrient and food intakes [26, 27]. The issue of accuracy of webbased self-reported data also arises for repeated 24-h dietary records compared to interviews by trained dietitians but previous work showed high agreement between the two methods in the case of our study [28].

Contrary to previous work, the definition of snacking was not based on food items consumed or the participant's self-definition of snacking. The fact that the volunteers did not declare snacking occasions as such (but only eating occasions in general) may have reduced the desirability bias, since snacking is often viewed as unhealthy behavior. Regarding socioeconomic data, a previous study showed that the quality of information provided by the web-based socio-demographic questionnaires used in the study was equal to or better than that of the paper-based questionnaire [23]. In addition, the large size of our sample may have been a constraint since significant results were found even when the difference between groups was small. However, the sample size and the diversity of collected data about demographic and socioeconomic factors enabled a highly accurate estimate and adjustment for several confounders. A major strength of our study lies in its reliance on several demographic factors and the use of the three major indicators of SEP. The use of demographic and socioeconomic indicators simultaneously allowed specific relationships to be highlighted which provide useful information to a better understanding of the mechanisms leading to social inequalities in health. The different parameters used to assess the nutritional quality of snack (energy intake, nutrient and energy densities) constitute an original contribution. Since the NRF9.3 $3_{100 \mathrm{kcal}}$ has been validated and can be applied to individual food, meals, menus, and even the daily diet, this nutrient index enabled us to assess the nutrient density of snacking occasions [34, 69]. The strength of this score lies in the fact that it includes both positive and negative components.

\section{Conclusions}

Our study highlights that snacking practices vary depending on demographic and socioeconomic factors. Age, education, and occupation appear to be predictors of occurrence of snacking. Having children in the household and low socioeconomic status seem to be associated with less healthy snacking behaviors. Better knowledge of the social disparities in snacking could help implementing public health policies, particularly in at risk populations. Further work assessing the mediating effect of snacking behaviors in the associations between socioeconomic position and weight and health status would be useful. 


\section{Additional files}

Additional file 1: Table S1. Medians and interquartile ranges of several snacking characteristics of participants in the NutriNet Santé Study included in the present study ${ }^{a}$. (DOCX $15 \mathrm{~kb}$ )

Additional file 2: Table S2. Associations ${ }^{a}$ between presence of child in the household and contribution ${ }^{b}$ of major foods groups to energy intake of daily snacks in women $\left(N_{\text {overall sample }}=84,962 ; N_{\text {snacking }}=62,209\right)$ and men $\left(\mathrm{N}_{\text {overall sample }}=23,491 ; \mathrm{N}_{\text {snacking }}=15,359\right)^{\mathrm{b}}$. (DOCX $\left.22 \mathrm{~kb}\right)$

\section{Abbreviations}

MDV: Maximum daily values; NRF9.3100 kcal: Nutrient-rich food index 9.3 per $100 \mathrm{kcal}$; RDV: Recommended daily values; SEP: Socioeconomic position

\section{Acknowledgments}

The authors thank the scientists, dietitians, technicians, and assistants who helped carry out the NutriNet-Santé Study. We especially thank Younes Esseddik, Thi Duong Van, Frédéric Coffinieres, Mac Rakotondrazafy, Régis Gatibelza, Paul Flanzy, Paul Flanzy, Mohand Ait Oufella, and Yasmina Chelghoum (computer scientists), Nathalie Arnault, Véronique Gourlet, Fabien Szabo, Charlie Menard, Laurent Bourhis (data-manager/biostatisticians), and the dieteticians Cédric Agaesse and Claudia Chahine, for their technical contribution to the NutriNet-Santé study. We thank all the volunteers of the NutriNet-Santé cohort. We are grateful to Valentin Partula for English editing of the manuscript.

\section{Funding}

Wendy Si Hassen was funded by a PhD grant from the Université Paris 13. The NutriNet-Santé study is supported by the following public institutions: Ministère de la Santé,Santé Publique France, Fondation pour la Recherche Médicale (FRM), Institut National de la Santé et de la Recherche Médicale (INSERM), Institut National de la Recherche Agronomique (INRA), Conservatoire National des Arts et Métiers (CNAM), and Université Paris 13. This research benefits from the joint assistance of the French National Health Insurance Fund for Employees (CNAMTS), the French Directorate General of Health (DGS), the Arc Foundation for Cancer Research, the French National Cancer Institute (INCA), Santé Publique France, the French National Institute of Health and Medical Research (INSERM), the French Inter-Departmental Agency for the Fight against Drugs and Addictive Behaviors (Mildeca), and the French Social Security Scheme for Liberal Professionals (RSI) as part of the "Primary Prevention" call for proposals issued by IRESP and INCA in 2013. The funders had no role in study design, data collection and analysis, decision to publish or preparation of the manuscript.

\section{Availability of data and materials}

Not applicable.

\section{Authors' contributions}

W.S.H. designed the study, performed statistical analysis, interpreted data and wrote the manuscript. K.C. was involved in the design of the study, interpretation of data, and helped to draft the manuscript. A.N. was involved in the statistical analysis. C.T., F.B. S.P., P.D. and A.L were involved in interpretation of data, and helped to draft the manuscript. S.H. designed and coordinated the cohort study and supervised the study. C.M. was involved in the conception and design of the study, supervision of statistical analysis and interpretation of data, and helped to draft the manuscript. All authors read and approved the final manuscript.

\section{Ethics approval and consent to participate}

This study was conducted according to the guidelines laid down in the Declaration of Helsinki, and all procedures were approved by the Institutional Review Board of the French Institute for Health and Medical Research (IRB Inserm No. 0000388FWA00005831) and the French Data Protection Authority (Commission Nationale Informatique et Libertés No. 908450 and No. 909216). Electronic informed consent was obtained from all participants.

\section{Consent for publication}

Consent form available upon request.

\section{Competing interests}

The authors declare that they have no competing interests.

\section{Publisher's Note}

Springer Nature remains neutral with regard to jurisdictional claims in published maps and institutional affiliations.

\section{Author details}

${ }^{1}$ Centre de Recherche en Epidémiologie et Statistique, Equipe de Recherche en Epidémiologie Nutritionnelle (EREN), Inserm (U1153), Inra (U1125), Cnam, Université Paris 13, 74 rue Marcel Cachin, F-93017 Bobigny, France.

${ }^{2}$ Université Libre de Bruxelles, Centre de Recherche en Epidémiologie, Biostatistique et Recherche Clinique, Ecole de Santé publique, Route de Lennik 808 - CP 598, 1070 Brussels, Belgium. ${ }^{3}$ Institut National de la Recherche Agronomique (INRA) - UR 1303 Alimentation et Sciences Sociales ALISS, 65 boulevard de Brandebourg, F-94025 Ivry sur Seine, France. ${ }^{4}$ Département de santé publique, Hôpital Avicenne, 125 rue de Stalingrad, F-93000 Bobigny, France. ${ }^{5}$ MOISA, INRA, CIRAD, CIHEAM-IAMM, Montpellier SupAgro, Université de Montpellier, Montpellier, France.

Received: 27 April 2017 Accepted: 23 February 2018

Published online: 15 March 2018

\section{References}

1. Bellisle F, Dalix AM, Mennen L, Galan P, Hercberg S, de Castro JM, Gausseres $\mathrm{N}$. Contribution of snacks and meals in the diet of French adults: a dietdiary study. Physiol Behav. 2003;79:183-9.

2. $\quad$ Piernas C, Popkin BM. Snacking increased among U.S. adults between 1977 and 2006. J Nutr. 2010;140:325-32.

3. Zizza C.; Siega-Riz A.M.; Popkin B.M. Significant increase in young adults' snacking between 1977-1978 and 1994-1996 represents a cause for concern! Prev Med 2001, 32, 303-310.

4. Kerver JM, Yang EJ, Obayashi S, Bianchi L, Song WO. Meal and snack patterns are associated with dietary intake of energy and nutrients in US adults. J Am Diet Assoc. 2006;106:46-53.

5. Miller R, Benelam B, Stanner SA, Buttriss JL. Is snacking good or bad for health: an overview. Nutr Bull. 2013;38:302-22.

6. Hess JM, Jonnalagadda SS, Slavin JL. What is a snack, why do we snack, and how can we choose better snacks? A review of the definitions of snacking, motivations to snack, contributions to dietary intake, and recommendations for improvement. Adv Nutr. 2016;7:466-75.

7. Bellisle F. Meals and snacking, diet quality and energy balance. Physio Behav. 2014:134:38-43.

8. Murakami K, Livingstone MB. Associations between meal and snack frequency and diet quality in US adults: National Health and nutrition examination survey 2003-2012. J Acad Nutr Diet. 2016;

9. Zizza CA, Arsiwalla DD, Ellison KJ. Contribution of snacking to older adults' vitamin, carotenoid, and mineral intakes. J Am Diet Assoc. 2010;110:768-72.

10. Zizza CA, Tayie FA, Lino M. Benefits of snacking in older Americans. J Am Diet Assoc. 2007;107:800-6

11. Drummond SE, Crombie NE, Cursiter MC, Kirk TR. Evidence that eating frequency is inversely related to body weight status in male, but not female, non-obese adults reporting valid dietary intakes. Int J Obes Relat Metab Disord. 1998:22:105-12

12. Ovaskainen ML, Reinivuo H, Tapanainen $H$, Hannila ML, Korhonen T, Pakkala $\mathrm{H}$. Snacks as an element of energy intake and food consumption. Eur J Clin Nutr. 2006;60:494-501

13. Hampl JS, Heaton CL, Taylor CA. Snacking patterns influence energy and nutrient intakes but not body mass index. J Hum Nutr Diet. 2003;16:3-11.

14. de Graaf C. Effects of snacks on energy intake: an evolutionary perspective. Appetite. 2006;47:18-23.

15. Prentice A, Jebb S. Energy intake/physical activity interactions in the homeostasis of body weight regulation. Nutr Rev. 2004:62:S98-104.

16. Plachta-Danielzik S, Landsberg B, Bosy-Westphal A, Johannsen M, Lange D, Muller J. Energy gain and energy gap in normal-weight children: longitudinal data of the KOPS. Obesity (Silver Spring). 2008;16:777-83.

17. Escalon H, Bossard C, Beck F. Baromètre santé 2008. Saint-Denis: INPES; 2009

18. Hartmann C, Siegrist M, van der Horst K. Snack frequency: associations with healthy and unhealthy food choices. Public Health Nutr. 2013;16:1487-96. 
19. Duffey KJ, Pereira RA, Popkin BM. Prevalence and energy intake from snacking in Brazil: analysis of the first nationwide individual survey. Eur J Clin Nutr. 2013:67:868-74.

20. Gazan R, Bechaux C, Crepet A, Sirot V, Drouillet-Pinard P, Dubuisson C, Havard S. Dietary patterns in the French adult population: a study from the second French national cross-sectional dietary survey (INCA2) (2006-2007). Br J Nutr. 2016;1 16:300-15.

21. Hercberg S, Castetbon K, Czernichow S, Malon A, Mejean C, Kesse E, Touvier M, Galan P. The Nutrinet-Sante study: a web-based prospective study on the relationship between nutrition and health and determinants of dietary patterns and nutritional status. BMC Public Health. 2010;10:242.

22. INSEE (French National Institute of statistics) definition of qualification level. Available online: https://www.insee.fr/en/metadonnees/definition/c1785. Accessed 12 Dec 2016

23. Vergnaud AC, Touvier M, Mejean C, Kesse-Guyot E, Pollet C, Malon A, Castetbon K, Hercberg S. Agreement between web-based and paper versions of a socio-demographic questionnaire in the NutriNet-Sante study. Int J Public Health. 2011;56:407-17.

24. INSEE (French National Institute of Statistics) Definition of occupational categories. Available online: https://www.insee.fr/fr/information/2497952. (Accessed on 28 June 2016)

25. INSEE (French National Institute of Statistics) Definition of consumption unit Available online: https://www.insee.fr/en/metadonnees/definition/c1802. (Accessed on 12 Feb 2015).

26. Lassale C, Castetbon K, Laporte F, Camilleri GM, Deschamps V, Vernay M, Faure P, Hercberg S, Galan P, Kesse-Guyot E. Validation of a web-based, selfadministered, non-consecutive-day dietary record tool against urinary biomarkers. Br J Nutr. 2015;113:953-62.

27. Lassale C, Castetbon K, Laporte F, Deschamps V, Vernay M, Camilleri GM, Faure P, Hercberg S, Galan P, Kesse-Guyot E. Correlations between fruit, vegetables, fish, vitamins, and fatty acids estimated by web-based nonconsecutive dietary records and respective biomarkers of nutritional status. J Acad Nutr Diet. 2015;116(3):427-38.

28. Touvier M, Kesse-Guyot E, Mejean C, Pollet C, Malon A, Castetbon K, Hercberg S. Comparison between an interactive web-based selfadministered $24 \mathrm{~h}$ dietary record and an interview by a dietitian for largescale epidemiological studies. Br J Nutr. 2011;105:1055-64.

29. Le Moullec N, Deheeger M, Preziosi P, Montero P, Valeix P, Rolland-Cachera MF, Potier de Courcy G, Christides JP, Galan P, Hercberg S. Validation du manuel photos utilisé pour l'enquête alimentaire de l'étude SU.VI.MAX. Cah Nutr Diet. 1996;31:158-64.

30. Arnault N, Caillot L, Castetbon K, Coronel S, Deschamps V, Fezeu L, Figuette M, Galan P, Guénard-Charpentier F, Hercberg S, Houet D, Julia C, KesseGuyot E, Lanotte M, Lisi A, Lucas F, Méjean C, Mohtadji A, Péneau S, Poulhès L, Salanave B, Tisseron E, Touvier M, Vernay M, Voegtlin C. Table de Composition des aliments NutriNet-Santé. Paris: Editions Économica; 2013.

31. Black AE. Critical evaluation of energy intake using the Goldberg cut-off for energy intake:basal metabolic rate. A practical guide to its calculation, use and limitations. Int J Obes Relat Metab Disord. 2000;24:1119-30.

32. Schofield WN. Predicting basal metabolic rate, new standards and review of previous work. Hum Nutr Clin Nutr. 1985;39:5-41.

33. Ello-Martin JA, Ledikwe JH, Rolls BJ. The influence of food portion size and energy density on energy intake: implications for weight management. Am J Clin Nutr. 2005;82:236S-41S

34. Fulgoni VL III, Keast DR, Drewnowski A. Development and validation of the nutrient-rich foods index: a tool to measure nutritional quality of foods. J Nutr. 2009;139:1549-54

35. U.S.Food \& Drug Administration Guidance for Industry: A Food Labeling Guide (14. Appendix F: Calculate the Percent Daily Value for the Appropriate Nutrients). Available online: https://www.fda.gov/downloads/ Food/GuidanceRegulation/GuidanceDocumentsRegulatorylnformation/ UCM265446.pdf. (Accessed on 2 Dec 2016).

36. Riou J, Lefevre T, Parizot I, Lhuissier A, Chauvin P. Is there still a French eating model? A taxonomy of eating behaviors in adults living in the Paris metropolitan area in 2010. PLoS One. 2015;10:e0119161.

37. Neumark-Sztainer D, Hannan PJ, Story M, Croll J, Perry C. Family meal patterns: associations with sociodemographic characteristics and improved dietary intake among adolescents. J Am Diet Assoc. 2003;103:317-22.

38. Sjoberg A, Hallberg L, Hoglund D, Hulthen L. Meal pattern, food choice, nutrient intake and lifestyle factors in the Goteborg adolescence study. Eur J Clin Nutr. 2003;57:1569-78.
39. Savige G, MacFarlane A, Ball K, Worsley A, Crawford D. Snacking behaviours of adolescents and their association with skipping meals. Int J Behav Nutr Phys Act. 2007:4:36.

40. Liu JL, Han B, Cohen DA. Associations between eating occasions and places of consumption among adults. Appetite. 2015;87:199-204.

41. Renner B, Sproesser G, Strohbach S, Schupp HT. Why we eat what we eat. The eating motivation survey (TEMS). Appetite. 2012;59:117-28.

42. Sonnentag S, Pundt A, Venz L. Distal and proximal predictors of snacking at work: a daily-survey study. J Appl Psychol. 2017;102:151-62.

43. O'Connor DB, Jones F, Conner M, McMillan B, Ferguson E. Effects of daily hassles and eating style on eating behavior. Health Psychol. 2008;27:S20-31.

44. Eldridge JD, Devine CM, Wethington E, Aceves L, Phillips-Caesar E, Wansink $B$, Charlson ME. Environmental influences on small eating behavior change to promote weight loss among black and Hispanic populations. Appetite. 2016;96:129-37.

45. Niven P, Scully M, Morley B, Baur L, Crawford D, Pratt IS, Wakefield M. What factors are associated with frequent unhealthy snack-food consumption among Australian secondary-school students? Public Health Nutr. 2015:18:2153-60.

46. Larson N, Miller JM, Eisenberg ME, Watts AW, Story M, Neumark-Sztainer D. Multicontextual correlates of energy-dense, nutrient-poor snack food consumption by adolescents. Appetite. 2017;112:23-34.

47. Pearson N, Griffiths P, Biddle SJ, Johnston JP, Haycraft E. Individual, behavioural and home environmental factors associated with eating behaviours in young adolescents. Appetite. 2017;112:35-43.

48. Ranjit N, Wilkinson AV, Lytle LM, Evans AE, Saxton D, Hoelscher DM. Socioeconomic inequalities in children's diet: the role of the home food environment. Int J Behav Nutr Phys Act. 2015;12(Suppl 1):S4.

49. Painter JE, Wansink B, Hieggelke JB. How visibility and convenience influence candy consumption. Appetite. 2002;38:237-8.

50. AFSSA - French Agency for Food, E.a.O.H.\&.S. Étude Individuelle Nationale des Consommations Alimentaires 2 (INCA 2) (2006-2007). Paris: AFSSA; 2009.

51. Lampure A, Deglaire A, Schlich P, Castetbon K, Peneau S, Hercberg S, Mejean C. Liking for fat is associated with sociodemographic, psychological, lifestyle and health characteristics. Br J Nutr. 2014;112:1353-63.

52. Kant AK, Graubard BI. 40-year trends in meal and snack eating behaviors of American adults. J Acad Nutr Diet. 2015;115:50-63.

53. Lhuissier A, Tichit C, Caillavet F, Cardon P, Masullo A, Martin-Fernandez J, Parizot I, Chauvin P. Who still eats three meals a day? Findings from a quantitative survey in the Paris area. Appetite. 2013;63:59-69.

54. Si HW, Castetbon K, Cardon P, Enaux C, Nicolaou M, Lien N, Terragni L, Holdsworth M, Stronks K, Hercberg S, Mejean C. Socioeconomic indicators are independently associated with nutrient intake in French adults: a DEDIPAC study. Nutrients. 2016;8:158.

55. Darmon N, Drewnowski A. Does social class predict diet quality? Am J Clin Nutr. 2008;87:1107-17

56. Irala-Estevez JD, Groth $M$, Johansson L, Oltersdorf U, Prattala R, Martinez-Gonzalez MA. A systematic review of socio-economic differences in food habits in Europe: consumption of fruit and vegetables. Eur J Clin Nutr. 2000:54:706-14.

57. Bozon M, Lemel Y. Les petits profits du travail salarié: moments, produits et plaisirs dérobés. Rev Fr Sociol. 1990:101-27.

58. Clendenen VI, Herman CP, Polivy J. Social facilitation of eating among friends and strangers. Appetite. 1994;23:1-13.

59. Kant AK, Graubard BI. Secular trends in the association of socio-economic position with self-reported dietary attributes and biomarkers in the US population: National Health and nutrition examination survey (NHANES) 1971-1975 to NHANES 1999-2002. Public Health Nutr. 2007;10:158-67.

60. McKinnon L, Giskes K, Turrell G. The contribution of three components of nutrition knowledge to socio-economic differences in food purchasing choices. Public Health Nutr. 1814-1824;2014:17.

61. Beydoun MA, Wang Y. Do nutrition knowledge and beliefs modify the association of socio-economic factors and diet quality among US adults? Prev Med. 2008;46:145-53.

62. Darmon N, Drewnowski A. Contribution of food prices and diet cost to socioeconomic disparities in diet quality and health: a systematic review and analysis. Nutr Rev. 2015;73:643-60.

63. Dijkstra SC, Neter JE, Brouwer IA, Huisman M, Visser M. Motivations to eat healthily in older Dutch adults-a cross sectional study. Int J Behav Nutr Phys Act. 2014;11:141.

64. Konttinen $\mathrm{H}$, Sarlio-Lahteenkorva S, Silventoinen K, Mannisto S, Haukkala A Socio-economic disparities in the consumption of vegetables, fruit and 
energy-dense foods: the role of motive priorities. Public Health Nutr. 2013; $16: 873-82$.

65. Inserm. Inégalités sociales de santé en lien avec l'alimentation et l'activité physique. Paris: Les éditions Inserm, 2014, XVI-731 p. - (Expertise collective). http://hdl.handle.net/10608/6522.

66. Allirot X, Saulais L, Seyssel K, Graeppi-Dulac J, Roth H, Charrie A, Drai J, Goudable J, Blond E, Disse E, Laville M. An isocaloric increase of eating episodes in the morning contributes to decrease energy intake at lunch in lean men. Physiol Behav. 2013;110-111:169-78.

67. Castetbon K, Vernay M, Malon A, Salanave B, Deschamps V, Roudier C, Oleko A, Szego E, Hercberg S. Dietary intake, physical activity and nutritional status in adults: the French nutrition and health survey (ENNS, 2006-2007). Br J Nutr. 2009;102:733-43.

68. Galea S, Tracy M. Participation rates in epidemiologic studies. Ann Epidemiol. 2007:17:643-53.

69. Drewnowski A. Defining nutrient density: development and validation of the nutrient rich foods index. J Am Coll Nutr. 2009;28:421S-6S.

Submit your next manuscript to BioMed Central and we will help you at every step:

- We accept pre-submission inquiries

- Our selector tool helps you to find the most relevant journal

- We provide round the clock customer support

- Convenient online submission

- Thorough peer review

- Inclusion in PubMed and all major indexing services

- Maximum visibility for your research

Submit your manuscript at www.biomedcentral.com/submit
C) Biomed Central 